Linguagem em (Dis)curso - LemD, v. 8, n. 2, p. 373-393, maio/ago. 2008

\title{
EM BUSCA DO GÊNERO LENDA URBANA
}

\author{
Carlos Renato Lopes*
}

\begin{abstract}
Resumo: O presente ensaio tem como objetivo situar, do ponto de vista teórico, um gênero narrativo em ampla circulação nas sociedades contemporâneas, em especial nos meios virtuais: as chamadas lendas urbanas. Num primeiro momento, são discutidas diferentes definições de lenda urbana - propostas dentro de campos de investigação distintos, como os estudos de folclore e a sociologia -, buscando-se dar ênfase aos aspectos discursivos implicados na constituição do gênero. Em seguida, são explorados os limites e intersecções entre esse e outros dois gêneros afins e freqüentemente confundidos: o rumor e o fait divers. Conclui-se a discussão por meio de uma revisão e questionamento da própria problemática da delimitação de um gênero discursivo.

Palavras-chave: gênero textual; lenda urbana; rumor; fait divers; discurso.
\end{abstract}

\section{INTRODUÇÃO}

As chamadas lendas urbanas, ou lendas contemporâneas, já há um tempo fazem parte de nosso cotidiano. Elas nos chegam em conversas com pessoas em que confiamos (ou não), nos jornais sensacionalistas e também nos mais sérios, nos e-mails encaminhados por dezenas de remetentes anteriores de quem nunca ouvimos falar, e até mesmo em filmes e outros produtos populares da mídia. Elas nos alcançam quando menos esperamos e, em alguns casos, mais do que provocar espanto ou surpresa, geram incredulidade e irritação, especialmente quando inundam nossas caixas de mensagens de correio eletrônico.

\footnotetext{
* Professor da Universidade Paulista (UNIP). Doutor em Letras Modernas. E-mail: <carelo@uol.com.br>.
} 
Mas o que são lendas urbanas? Uma primeira definição, digamos, intuitiva poderia ser formulada nos seguintes termos: são histórias que envolvem elementos ou situações banais do cotidiano, mas que por seu caráter inusitado, ou em muitos casos absurdo, provavelmente não aconteceram. No entanto, são contadas como se tivessem de fato acontecido, não diretamente a seus narradores, mas a alguém por eles conhecido ou a eles ligado. Quando um conhecido nos conta, por exemplo, que alguém foi contaminado por uma agulha infectada com o vírus HIV ao sentar-se numa cadeira de cinema, ou ao enfiar o dedo no lugar de onde saem as moedas de troco em um telefone público, dificilmente saberemos quem é essa pessoa, seu nome, onde mora. Nosso conhecido nos dirá que aconteceu com "um amigo de um amigo", ou que ouviu contarem isso numa festa, ou em conversa ao redor do bebedouro, no cafezinho.

Este trabalho é composto de três movimentos interligados. Num primeiro momento, fazemos um levantamento de como o gênero lenda urbana tem sido definido em diferentes campos de pesquisa, com um olhar particular para a questão da linguagem e do discurso. Num segundo momento, traçamos uma correlação entre lendas urbanas, fait divers e rumores, investigando as semelhanças e diferenças entre esses diferentes gêneros, que freqüentemente se interpenetram nas práticas discursivas de transmissão e recepção das lendas. Finalmente, reavaliamos o conceito de gênero propriamente dito, buscando desconstruir a noção de categoria fechada ou forma estável que se poderia associar ao conceito.

\section{DEFINIÇÕES DE LENDA E LENDA URBANA DOS FOLKLORE STUDIES}

Antes de mais nada, há o conceito de lenda. Embora já se tenha dito que é impossível definir realmente o que é uma lenda, as tentativas continuam surgindo. Já na década de 1970, um folclorista, consciente desse fato, chegou a propor a involuntariamente engraçada definição de lenda como 
[...] uma história ou narrativa que pode nem mesmo ser uma história ou narrativa; ela se dá em um passado histórico recente que pode ser concebido como remoto ou anti-histórico, ou nem mesmo em um passado; ela é tida como verdadeira por alguns, falsa por outros, e ambos ou nenhum dos dois pela maioria. (GEORGES, 1971 apud BRUNVAND, 2002, p. 112) ${ }^{1}$

Mas, se a definição pode ser interessante pelas próprias contradições que comporta, ela não parece ter sido levada muito a sério.

Em uma linha mais conciliatória, Dégh (2001) faz um levantamento, em ordem cronológica, das definições de lenda e lenda contemporânea propostas por estudiosos europeus e norte-americanos no último século, a fim de identificar, para além das discordâncias, alguns elementos de intersecção.

Revisando a tradição filológica germânica do estudo de lendas, a autora identifica já dois aspectos bastante recorrentes: a crença e o medo, ambos discutidos nos trabalhos de Röhrich (1988 apud DÉGH, 2001), por exemplo. Esse autor reitera a idéia de que "a lenda demanda do contador e do ouvinte a crença na verdade do que se conta", e que as pessoas contam lendas a fim de "verbalizar ansiedades e medos e, ao explicá-los, liberar-se do poder opressivo de seus medos" (p. 37). Elaborando de uma forma mais dialética a noção da crença associada à lenda, Gerndt (1991 apud DÉGH, 2001) postula que as lendas aspiram a ser diretamente ou indiretamente verdadeiras e informar sobre um evento passado verdadeiro, acrescentando: "Uma história se torna uma lenda somente se for apresentada na zona intersticial entre a crença e a dúvida" (p. 38).

A tradição das abordagens anglo-americanas não revelaria questões substancialmente diferentes, a não ser pela ênfase maior na questão da crença na verdade das narrativas. Como novidade a se destacar, porém, há a inclusão do aspecto social da transmissão e recepção das lendas, assim formulado por Dorson:

Uma vez que se propõem históricas e factuais, [as lendas] devem ser associadas na mente da comunidade com algum indivíduo conhecido, marco geográfico ou episódio particular. Todos ou muitos dos membros de um dado grupo social terão ouvido falar

\footnotetext{
${ }^{1}$ São nossas, todas as traduções de citações de obras consultadas originalmente em inglês.
} 
da tradição e podem se lembrar dela de forma breve ou elaborada. Esse é de fato um dos principais testes da lenda: que ela seja conhecida por um número de pessoas unidas em sua área de residência, ocupação, nacionalidade ou crença. (DORSON, 1968 apud DÉGH, 2001, p. 43)

A problemática da definição, porém, torna-se mais complexa quando entram em cena as lendas contemporâneas. Uma das dificuldades parece ser a de encontrar o que realmente distingue a versão contemporânea da não-contemporânea. Além disso, existe a questão dos vários gêneros e subgêneros que são freqüentemente associados à lenda contemporânea. Tall tales, rumors, belief stories, anecdotes, scary stories e bogus warnings são apenas alguns dos exemplos de terminologias que encontramos na literatura em língua inglesa.

De qualquer maneira, alguns novos conceitos começam a ganhar ênfase nos esforços definidores. Destacamos, desse conjunto, cinco definições de lenda urbana, ou lenda contemporânea ${ }^{2}$, cada qual enfatizando um aspecto de suas possíveis frentes de abordagem. Analisamos, a seguir, as três primeiras de um modo mais geral e as últimas duas em mais detalhe, não com o intuito de fechar questão sobre uma ou outra, mas antes ressaltar elementos de caráter mais discursivo, que é o foco principal desta investigação.

\section{DEFINIÇÃO 1: LENDA EM CONTEXTO}

Fine (1992), embora reconhecendo as limitações da tarefa que consiste em descrever formalmente um gênero, propõe uma descrição operacional de lenda contemporânea que comporta alguns elementos que nos interessam mais de perto. Para o sociólogo, a lenda contemporânea é

\footnotetext{
2 A propósito, os termos "urbana" e "contemporânea" ambos apresentam problemas. O primeiro se tornou mais popular graças em parte às coletâneas de Brunvand $(1981$; 2002) publicadas desde a década de 1980. Alguns teóricos, no entanto, o rejeitam por acreditar que as histórias não se circunscrevem ao universo das cidades. Já o segundo termo, preferido por autores como Ellis (2001) e ratificado pela International Society for Contemporary Legend Research, criada no início dos anos 1990 (FINE, 1992), pode levar à falsa impressão de que se trata apenas de histórias recentes, quando muitas delas têm suas raízes em tradições antigas. Em defesa desse termo, porém, há a idéia de que qualquer história é percebida como contemporânea à época em que circula. (ELLIS, 2001) Ao longo deste trabalho, privilegiamos o primeiro termo, ainda que consciente de suas limitações.
}

LOPES - Em busca do gênero... 
[...] uma narrativa que um contador apresenta a uma platéia no contexto de seu relacionamento. O texto é um relato de um acontecimento no qual o narrador ou um contato pessoal imediato não esteve envolvido, e é apresentado como uma proposição para a crença; não é sempre tido como verdadeiro pelo falante ou platéia, mas é apresentado como algo que poderia ter ocorrido, e é contada como se tivesse acontecido. As ocorrências são eventos notáveis do tipo dos que são supostamente 'estranhos mas verdadeiros'. (p. 2)

Destacamos nessa definição, em primeiro lugar, a idéia de que a lenda circula em uma comunidade, isto é, num contexto reconhecível a membros de uma comunidade. Portanto, quem a conta faz parte também dessa comunidade e compartilha com ela suas práticas discursivas e suas regras de funcionamento - regras essas mais ou menos conscientes, mais ou menos anônimas.

A chamada proposição para a crença inclui-se aí nessas regras. Trata-se de um pacto que os membros da comunidade se propõem a fazer, ainda que não tomem como verdadeiras as histórias que fazem circular. Já se tem aí um primeiro questionamento quanto à necessidade da comprovação factual do conteúdo narrado pelas lendas: podemos entender pela sentença final que o supostamente se aplica tanto a elas serem estranhas, quanto verdadeiras.

\section{DEFINIÇAO 2: LENDA COMO RESPOSTA COLETIVA}

Wycoff (1993 apud DÉGH, 2001) também considera a transmissão de lendas como prática dentro de uma comunidade. Sua definição, no entanto, vai mais além, ao afirmar sobre as lendas contemporâneas:

[...] aquelas histórias-rumores de base lingüística, narráveis, apócrifas e geralmente anônimas que relatam eventos relativamente atuais e ostensivamente verdadeiros circulam freqüentemente no interior de uma comunidade como parte de uma resposta coletiva, criativa e inconsciente a alguma questão da comunidade, ainda que codifiquem simbolicamente as ambigüidades sociais que subjazem essa questão. (p. 45) 
A autora propõe a idéia de que as lendas articulam questões com as quais a comunidade se vê às voltas para explicar. Podemos aqui interpretar essas questões como sendo medos, ansiedades, polêmicas e interditos que uma sociedade precisa simbolizar, até certo ponto inconscientemente, na forma de narrativas. Essas narrativas viriam então confirmar ou questionar concepções de mundo tidas como válidas dentro da comunidade em questão. A definição de Wycoff dialoga, em certo sentido, com duas outras formulações: a de Röhrich (apud DÉGH, 2001), já citada acima, e a de Whatley e Henken (2000), na qual defendem a idéia de que mais importante que a verdade objetiva ou científica por trás da lenda talvez seja “a 'verdade' que o folclore transmite sobre as atitudes, medos e crenças de um grupo, as quais, por sua vez, moldam e mantêm a identidade daquele grupo" (p. 5).

\section{DEFINIÇAOO 3: LENDA ENTRE O MUNDANO E O EXTRAOR- DINARIO}

Já Smith (1995, apud DÉGH, 2001) enfatiza uma outra característica importante da lenda: o fato de estar entre planos de representação. Diz o folclorista:

[A]s lendas contemporâneas se situam em algum lugar entre o mundano, as experiências cotidianas e o extraordinário. Se preferirem, elas dizem respeito ao mundano e o ordinário, porém com um toque inusual. E é sua natureza mundana que fornece a elas uma qualidade única que as diferencia das outras formas de narrativa tradicionais. (p. 45)

As lendas contemporâneas são, sob esse ponto de vista, histórias ambivalentes, que lidam com elementos imediatamente reconhecíveis e cotidianos (o mundano), mas que estão de algum modo "fora da ordem" (o extraordinário). A idéia remonta a Aristóteles, que em sua Arte Poética já propunha que a narrativa, ao mesmo tempo em que exige um elemento de reconhecimento, algo que nos soa familiar e conhecido - ou "o que faz passar da ignorância ao conhecimento" (ARISTÓTELES, s.d., p. 255) -, também nos apresenta uma reversão, uma mudança no sentido contrário do destino, a chamada peripécia. Na lenda, reconhecese alguma coisa ao mesmo tempo em que se estranha alguma coisa. Essa característica de estar entre dois planos de representação - o que 
configura seu caráter único e singular - relaciona-se ao fato de as lendas se situarem, enquanto práticas discursivas, entre a estrutura (a regularidade, a sistematicidade, relativas à ordem do discurso) e o acontecimento (o particular, relativo à ordem da enunciação).

Ainda que alguns dos termos propostos exijam uma maior qualificação (em especial, o que Wyckoff chama de "eventos ostensivamente verdadeiros"), nas três definições acima encontramos elementos que concorrem para aproximar, com ênfases e de formas diferentes, o material narrado ("parte de uma resposta coletiva, criativa e inconsciente"), o narrador ("falante", "contador") e a comunidade com a qual interage ("seu contexto de relacionamento"). Isso aponta para uma visão mais discursiva do fenômeno das lendas, colocando-as como práticas sociais reconhecíveis ("do mundano e do ordinário”) e compartilhadas por sujeitos sócio-histórico-ideologicamente situados. A abordagem do fenômeno por aqueles autores não se coloca explicitamente nesses termos, mas definitivamente sugere pontes com pressupostos de linhas teóricas como a Análise do Discurso, em suas versões crítica ou "francesa".

\section{DEFINICÃO 4: LENDA COMO GÊNERO "EMERGENTE"}

Pudemos observar como estudiosos de diferentes áreas começaram nas últimas décadas a definir as lendas urbanas como processos comunicativos, não formas estáticas. De fato, para Ellis (2001), as lendas contemporâneas se constituem como formas emergentes, na medida em que surgem dentro de contextos sociais os quais elas pretendem alterar. Esse caráter emergente das lendas urbanas se dá, segundo o autor, em três níveis.

Primeiro, as lendas urbanas emergem como "notícias fresquinhas" no contexto social de quem as conta. Embora seus temas e sua estrutura possam ser bem antigos, os eventos ou crenças que elas abordam se apresentam como relevantes, na medida em que dizem respeito ao passado, presente e futuro do ouvinte/leitor.

Em um segundo nível, as lendas são emergentes na medida em que seus significados mais elementares derivam de condições e papéis sociais determinados. Consideram-se aqui, por um lado, as razões pelas quais alguém conta uma lenda, e o controle da situação e o poder de 
transformação de estruturas sociais que essa(s) pessoa(s) pode(m) ou não exercer ao fazê-lo; e, por outro, as expectativas que as platéias têm do evento e o modo como podem influenciar e redirecionar o processo narrativo como um todo. Como bem coloca o autor:

As lendas normalmente fazem parte de uma discussão contínua e estão constantemente sujeitas a contribuições, correções, comentários e objeções de outros participantes. Diferentemente dos contos, que em geral são separados de uma conversação normal e ouvidos sem interrupções, as lendas devem ser vistas como parte de um evento comunitário, em que o papel do público é tão importante quanto o dos narradores. (ELLIS, 2001, p. 10)

Aqui, reforça-se a idéia de que a lenda não é nunca um texto completo, contido em si mesmo, mas sim parte de uma conversa continuada - ainda que na forma escrita - e, portanto, ela não pode ser descolada das circunstâncias que lhe dão corpo, isto é, de sua performance. Essa performance, motivada pelas preocupações e aspirações locais daquele grupo em que a lenda circula, será mais ou menos longa e detalhada, mais ou menos acalorada, dependendo dos interesses dessa mesma comunidade. Em outras palavras, a "vida" de uma lenda não se limita de uma vez por todas a essa circulação local, mas reinscreve-se sempre, reencena-se e toma corpo e voz só mesmo aí num tal espaço, nessa prática discursiva.

Finalmente, as lendas urbanas incorporam um elemento de emergência no sentido de urgência - por exemplo, ao descrever um problema social que precisa de atenção urgente da comunidade. Ainda que esse sentido de urgência tenda a desaparecer à medida que as "últimas" (mais recentes) lendas vão sendo rapidamente "desbancadas" e outras novas vão surgindo e lhe roubando a atenção, deve-se combater, segundo Ellis, a postura simplista de folcloristas que, ao decretarem de antemão a falsidade das histórias, ignoram aspectos complexos do contexto sócio-histórico em que elas se inserem.

Essa tentativa de trazer o contexto - as condições de produção e recepção - para dentro da própria caracterização do gênero certamente aproxima a tese de Ellis de uma abordagem discursiva. Assim, explorar as possíveis aproximações entre essas posições teóricas se coloca como uma tarefa promissora. 


\section{DEFINIÇCAO 5: LENDA COMO DLALÉTICA}

Igualmente instrumental é a proposição de Dégh (2001) de "lenda" - termo abrangente que ela prefere usar para suas diferentes versões - como gênero "conversacional, dialético e polifônico" por definição. Para a autora, a lenda, mais que qualquer outro gênero do folclore, só pode fazer sentido dentro de um fogo cruzado de controvérsias. Ainda que os interlocutores não expressem particularmente qualquer resistência ou discordância em relação à proposição da lenda, a já esperada voz opositiva da sociedade se faz sentir de um modo ou de outro. Quando, por exemplo, um narrador descreve uma situação extraordinária ou francamente inusitada, ele tem certa consciência das resistências e objeções que poderá gerar na platéia e, assim, pode antecipar em sua formulação uma contra-argumentação (algo como "Eu sei que é difícil acreditar nisso, mas tal fato realmente ocorreu..."). Tal resistência pode até mesmo não ser verbalizada diretamente por membros da platéia (ou ser expressa por outros meios), mas ela existirá sempre em estado potencial.

Dégh (2001) coloca a disputa - o "ressoar de opiniões contrárias" - não apenas como mais um elemento da lenda, mas sim sua própria razão de ser. Em suas palavras:

Toda afirmação que contraria noções tidas como racionais ou autênticas, ou crenças que são canonizadas e portanto quase racionais, traz em si sua própria dialética. Essa antecipação incorporada da contradição é o principal identificador da lenda, distinguindo-a de outros gêneros do folclore. (p. 2)

Ora, torna-se visível aqui o nexo existente entre essas idéias e os princípios do dialogismo de Bakhtin (1934-1935/1990; 19521953/2000). Conforme sugerido pelo teórico russo, todos os gêneros são dialógicos no sentido de que "conversam entre si", incorporando marcas de seu exterior em seu interior de modo constitutivo. Isso equivale a dizer que em todo enunciado é possível ver ressoar, de modo mais ou menos perceptível, as palavras do outro, com as quais ele vem estabelecer uma relação de dialogismo. Além disso, a relação de alteridade se dá não apenas entre um enunciado e os que o precedem, 
mas também entre um enunciado e os que lhe sucedem na cadeia da comunicação verbal.

De fato, o domínio que os falantes aprendem a ter dos diferentes gêneros do discurso ao longo da vida lhes permite moldar suas falas às formas desses gêneros, isto é, adaptar-se a sua extensão, entonação ou gravidade. Ao mesmo tempo, isso só pode ocorrer se se levar em conta o outro e o porvir de sua resposta. Assim, o gênero "lenda" conforme definido por Dégh (2001) revela de maneira explícita uma relação dialógica, na medida em que ele se sustenta na alteridade, ou seja, traz para si já anunciada a voz do "outro" - esse outro que no fluxo da cadeia de comunicação se opôs ou irá se opor a ele, ainda que para apenas acrescentar uma nova contribuição ou versão recontada da "mesma história".

Avançando nessa discussão sobre o gênero, retomemos aqui o pensamento de Ellis (2001) a respeito da performance das lendas, para traçar uma conexão entre sua definição e a de Dégh logo acima. Trata-se de reconhecer o fato de que as práticas discursivas em que emergem e circulam as lendas urbanas podem, elas mesmas, ser bastante variadas. As lendas podem estar encaixadas em uma conversa cujo tema principal não seja a lenda propriamente dita; podem vir na forma de um "conto de precaução" (cautionary tale); podem suscitar uma ação imediata, como no caso das correntes via Internet; ou podem ainda se resumir a uma espécie de "lenda-rumor", algo na linha de: "Você sabia que essa canção dos Beatles, quando tocada ao contrário, revela uma mensagem demoníaca anunciando a morte de Paul McCartney?", ou "Os hambúrgueres do McDonald's não são feitos de carne bovina, mas de minhoca".

Conforme aponta Ellis (2001), não existem histórias "básicas", subjacentes em uma estrutura profunda, a partir das quais vão surgindo versões diferentes, mas sim um conjunto ilimitado de possíveis narrativas com o qual o intérprete (seja ele o estudioso, o contador de histórias, ou a própria platéia) pode vir a associá-las. E acrescenta:

O que é mais importante: existe também um conjunto ilimitado de narrativas possíveis que cada uma das partes poderia construir no futuro em resposta a essas narrativas existentes. Isso quer dizer que o que quer que proponhamos como sendo 'uma lenda' não é uma trama subjacente mas sim um ímpeto social de criar novas narrativas no formato das antigas. (p. 8) 
Isso vem mais uma vez afirmar a idéia de que o estudo de tais narrativas não se deve ater a textos fechados, isto é, versões estruturadas ou resumidas de histórias tais como são apresentadas por folcloristas nas enciclopédias do gênero. Como toda narrativa, de resto, as lendas urbanas devem ser estudadas como performances em processos sociodiscursivos, com atenção especial aos mecanismos de produção/recepção que lhes permitem circular, aos elementos contingenciais de sua enunciação, bem como às questões ideológicas indissociáveis desses processos. Segundo Ben-Amos (1972, apud ELLIS, 2001), o folclore, domínio no qual o estudo das lendas tradicionalmente se situa, não se pode resumir a um amontoado de textos impressos tomados isoladamente e em abstrato, mas sim deve ser visto como um processo comunicativo localizado em um contexto cultural determinado. Dentro dessa perspectiva, nos diz o autor, "a narração é a narrativa; portanto, o narrador, sua história e seu público estão todos relacionados entre si como componentes de um único contínuo" (p. 4).

Com efeito, a prática de contar e discutir lendas urbanas nos posiciona como sujeitos cujo papel vai além do julgamento imediato da veracidade ou falsidade das histórias. Essa prática pode nos ajudar a perceber, conforme sugerido na definição 2 acima, o que é que em nosso "mundo cotidiano" tanto mobiliza a circulação de tais histórias; perceber que anseios, que preocupações e que questões estão em jogo; perceber, enfim, que discursos estão sendo construídos e (re)afirmados através dessas histórias. O que leva Ellis (2001) a propor uma abordagem do gênero particularmente inspiradora. Sugere o autor que perguntemos não que fórmulas as lendas contêm, mas o que essas fórmulas corporificam. Isso implica responder à questão: $\mathrm{O}$ que as pessoas estão fazendo quando contam lendas? Certamente não estão simplesmente trocando histórias curiosas ou inusitadas de maneira inocente. Estão compartilhando visões sobre eventos que reconhecem como fazendo parte significativa do mundo que habitam, ainda que de modo potencial ou especulativo. Daí que as narrativas - incluídas aí as lendas urbanas - "sobrevivem em parte porque elas nos lembram do que sabemos e em parte porque elas nos chamam de volta para aquilo que nós consideramos significativo" (FULFORD, 1999, p. 3). 
Dégh (2001) vai mais longe, ao afirmar que as lendas tratam de preocupações universais, das questões mais cruciais do mundo e da vida humana. Segundo a autora, as lendas suscitam perguntas do tipo:

A ordem do mundo é mesmo essa que nos ensinaram? Podemos esperar que a vida irá seguir seu curso como aprendemos que ela deveria? Nós conhecemos as forças que regulam o universo e a nossa vida, ou existem dimensões escondidas que podem desviar o fluxo causal e racional das coisas? E se há forças desconhecidas, podem elas ser identificadas, alteradas, evitadas ou exploradas em nosso benefício? (p. 2)

Ceticismo, ironia, ansiedade, pavor: seja qual for a atitude que adotemos diante das lendas urbanas e sua "improvável veracidade", ela haverá de ser resultado de um reconhecimento e ao mesmo tempo de um desconforto com algo que "não se encaixa bem" na ordem das coisas que cremos natural.

\section{LENDAS, RUMORES E FAIT DIVERS}

Vimos como as lendas urbanas, ao estarem inscritas em processos discursivos mais amplos que o simples "contar uma história", podem assumir modalidades distintas de expressão, não sendo redutíveis a uma história básica subjacente. Duas dessas modalidades discursivas nos retêm a atenção do modo particular: os rumores e os fait divers. Nesta seção, discutimos cada uma delas em detalhe a partir de um levantamento teórico.

Alguns folcloristas propõem definir rumor como um gênero à parte, com características formais próprias que o distinguem da lenda. Brunvand (1981), por exemplo, define rumor como um "relato breve, anônimo e não-verificado de um suposto acontecimento que circula de boca em boca ou pela mídia" (p. 194). Diferentemente da lenda, o rumor tende a ser não-narrativo e ter vida curta, embora possa contribuir para o crescimento e difusão de uma lenda. Klintberg (1985 apud DÉGH, 2001), por sua vez, enfatiza justamente o aspecto da difusão como sendo a marca principal do rumor - que muitas vezes se resume a uma simples declaração -, em oposição ao conteúdo narrativo, que caracteriza a lenda. 
Outros estudiosos, no entanto, postulam haver uma diferença muito pouco substancial, ou no mínimo nebulosa, entre lenda e rumor. Fine (1992), entre eles, aponta para a chamada "estrutura de credibilidade", isto é, o fato de que ambos se caracterizam por uma proposição à crença. Além disso, tanto a lenda quanto o rumor podem mobilizar conteúdos tradicionais e ecoar aspectos da situação social imediata dos falantes/ participantes do processo de transmissão (p. 2-3). Para o autor, os dois gêneros parecem tão imbricados que, com freqüência, é difícil saber onde termina um e onde começa o outro. De fato, é comum a percepção de que os temas mais ou menos limitados e previsíveis dos rumores possam vir a se expandir em lendas, na medida em que sobrevivam à sua breve realização assumindo um caráter mais narrativo e ganhando longevidade dentro de uma determinada tradição cultural.

Entretanto, a pergunta se coloca: como sabemos se uma lenda é sobrevivente de um rumor? Em outras palavras, como identificar o momento em que um rumor deixa de ser rumor e assume o "estatuto" de lenda? Essa dificuldade epistemológica se manifesta, como bem aponta Dégh (2001), no trabalho de pesquisadores, jornalistas e estudantes da área, que perseguem avidamente os meandros que tais relatos assumem nos mais diversos canais de comunicação contemporâneos em busca de uma "lenda em emergência" - para no fim descobrirem que muitos deles não ultrapassam a barreira de sua própria efemeridade, ou seja, não se tornam lendas, quer porque são desbancados com a mesma velocidade com que se difundem, quer porque novos rumores lhes vêm substituir, quer ainda porque não repercutem de modo mais intenso além dos limites de uma ou outra comunidade discursiva.

Mas para não nos restringirmos ao âmbito dos estudos de folclore, caberia mencionar a interessante discussão proposta por Orlandi (2001) a respeito dos boatos. Segundo a autora, a formulação desses burburinhos, desses relatos surdos não comprovados, é o anúncio da chegada de um discurso, o que possibilitará a construção, em forma de texto, de um dizer a partir de um "fato". Os boatos seriam uma forma de discurso "à procura de uma memória (de um saber dizer), para produzir o efeito de estar em uma filiação, uma rede de significação constituindo uma tradição de sentidos possíveis, até mesmo necessários" (p. 136). Assim, arriscaríamos 


\section{6}

dizer que é na medida em que deixam um rastro permanente, que encontram e se filiam a essa memória, que os boatos podem produzir um efeito de verdade que os "promova" ao estatuto de lenda dentro de uma tradição de sentidos plausiveis.

Reportando ainda essa última discussão ao que diz Dégh (2001) sobre os rumores assustadores que envolvem ameaças à segurança de indivíduos e grupos - como os vírus de computador, o roubo de órgãos para tráfico, os cultos satânicos, entre vários outros -, é possível dizer que quanto mais "perigosos e virulentos" forem esses rumores, ainda que em sua mínima elaboração narrativa, maiores as chances de eles se articularem aos temas poderosos que concernem aos "medos do momento" e de se desenvolverem em mininarrativas improvisadas e adaptativas, como espécies de "agregados de lendas contemporâneas".

Lendas podem se desenvolver também a partir de material jornalístico. É comum que agências de notícias ou jornais (não necessariamente sensacionalistas ${ }^{3}$ ) dediquem uma seção regular a histórias do cotidiano com algum conteúdo curioso, inusitado, que chame a atenção pela articulação de elementos a princípio incongruentes em sua própria composição. Esse tipo de notícia ecoa o que se chama em francês de fait divers - algo como "fato curioso", ou "curiosidade", em português.

Segundo Barthes (1966/2003), que discutiu o gênero em um de seus inúmeros ensaios, o fait divers não apresenta um conteúdo que seja propriamente estranho ao mundo. Acidentes, roubos, assassinatos, "esquisitices" e outros temas típicos do fait divers, remetem ao homem, "a sua história, a sua alienação, a seus fantasmas, a seus sonhos, a seus medos" (p. 58). Porém, o que o torna notável é a relação que ele articula entre os elementos enunciados, remetendo para si próprio todo o efeito de surpresa, choque ou horror. O autor dá como exemplo o seguinte enunciado: "Empregada rapta o bebê de seus patrões". Em função do estereótipo, faz-se crer imediatamente que se trata de um seqüestro convencional com um único objetivo: um resgate. No entanto, o que permitiu que o fato se tornasse notícia foi a quebra do estereótipo: a empregada raptou a criança por amá-la demais e querer tomá-la para si.

\footnotetext{
${ }^{3}$ É o caso, por exemplo, do site da Reuters na Internet, que publica uma seção diária chamada Oddly Enough.
}

LOPES - Em busca do gênero... 
Ocorre aqui o que Barthes chama de causalidade desregulada: um evento prosaico, de causa cultural e socialmente presumível, torna-se um acontecimento importante - ou pelo menos digno de nota, newsworthy pela reversão (muitas vezes decepcionante) do estereótipo no momento em que são reveladas as motivações reais desse evento. Tal reversão, porém, longe de enfraquecer o impacto da notícia, reforça-a em pelo menos dois aspectos: por um lado, cria um efeito segundo o qual as causas dos eventos podem estar em toda a parte - num mundo saturado de signos, cujo poder é infinito e onipresente -, potencialmente ligando o homem a qualquer elemento do cotidiano; mas, por outro lado, ocasiona a perda do controle dessa mesma causalidade na medida em que esta se submete a forças que lhe escapam. Nos dizeres de Barthes:

[...] perturbada sem entretanto desaparecer, [essa causalidade] fica de certo modo suspensa entre o racional e o desconhecido, oferecida a um espanto fundamental; distante de seu efeito (e é isto, no fait divers, a própria essência do notável), a causa aparece fatalmente penetrada por uma força estranha: o acaso; no fait divers, toda causalidade é suspeita de acaso. (BARTHES, 1966/2003, p. 63)

Ora, estamos diante de um universo que, ao menos potencialmente, nos convida a transformar rumores em lendas, fatos curiosos e efêmeros em histórias mais duradouras. O que permite que essas histórias permaneçam talvez seja a necessidade que as sociedades contemporâneas têm de fazer sentido desse mundo povoado de signos ao mesmo tempo reconhecíveis e incertos; confortantes, na medida em que remetem a um mundo repleto de sentido(s), e insondáveis, na medida em que escapam das formas mais convencionais e estereotípicas da cultura, buscando, no percurso, tornar-se símbolos.

Cria-se, assim, uma espécie de ironia quando se pensa na lenda como uma história velha vestida de nova, uma vez que, para os que aderem a seu processo de transmissão/recepção, o que a torna material digno de nota é o fato de emergir como "notícia fresquinha". Dégh (2001) chama a atenção para esse efeito, lembrando que "[O]s assinantes de jornais locais podem até gostar de ler sobre mistérios passados, mas com seu café da manhã o que querem é ser informados sobre as novas 'bombas' (new shockers)" (p. 170-1). 


\section{DESCONSTRUINDO O CONCEITO DE GÊNERO}

Caberia, a essa altura, recompormos a discussão em torno da questão mesma da categorização genérica. E uma pergunta logo se impõe: o que surge primeiro, uma história particular ou um gênero? $\mathrm{O}$ ovo ou a galinha? Bruner (1996/2001) nos lembra que estudiosos vêm tentando, desde a época de Aristóteles até os dias de hoje, decidir se os gêneros "geram" histórias particulares - levando à interpretação de seqüências de eventos de acordo com sua prescrição genérica - ou se eles são "meros pensamentos a posteriori que ocorrem para organizar as mentes acadêmicas" (p. 129).

Com efeito, é possível observar como histórias particulares tendem a ser interpretadas como se se encaixassem em gêneros preexistentes, evocando fórmulas tais quais: "o bem vence o mal", "o feitiço vira contra o feiticeiro", "a curiosidade mata", "mentira tem perna curta", "o castigo vem a galope", entre tantas outras. Não seria possível começar a interpretar qualquer forma narrativa se não lançássemos mão de um suporte de conhecimento prévio sobre categorias preconcebidas, os chamados gêneros. Na definição do autor, os gêneros seriam "formas culturalmente especializadas de vislumbrar a condição humana e de comunicá-la" (BRUNER, 1996/2001, p. 129). No trabalho de interpretação do mundo, acabamos por "não resistir" à imposição de categorias genéricas aos personagens e situações que nos rodeiam na vida cotidiana, assimilando-os aos formatos que a cultura desenvolveu e consolidou.

O que faz com que os gêneros tenham um caráter social e historicamente determinado é o fato de estarem ligados a instâncias concretas de produção de linguagem. " $[\mathrm{E}] \mathrm{m}$ vez de uma forma na qual se viriam alojar os conteúdos ideológicos, o gênero já é uma interpretação do real a partir de um lugar de produção de linguagem" (GRILLO, 2004, p. 46). Essa interpretação do real se substancializa, por sua vez, sob a forma de regularidades, especificidades e convencionalidades que se constituem como parâmetros interpretativos inscritos num cânone, numa memória discursiva acessível aos membros da comunidade que compartilham daquele gênero. E o reconhecimento dessas regularidades torna possível, ainda que provisória, a "ancoragem interpretativa" que 
diferencia um gênero do outro, tanto em sua produção quanto em sua recepção.

No entanto, não se pode pensar no gênero como uma força meramente conservadora. Da mesma forma em que tende a uma estabilização, essa força é submetida a contínuos deslocamentos em virtude mesmo de sua inserção numa determinada prática sóciohistórico-culturalmente localizada (PINHEIRO, 2002). Uma prática, bem entendido, que envolve a língua, a história e os sujeitos. Essa dupla natureza do gênero, em sua força tanto de estrutura (reguladora) quanto de acontecimento (transformador), é resumida por Gregolin nos seguintes termos:

O gênero é, portanto, um operador da memória social que permite as retomadas e os deslocamentos de sentidos, que distribui papéis e institui lugares que podem ser ocupados por sujeitos historicamente situados. Assim, muito mais do que uma pura forma concluída, ele é um espaço móvel onde vêm-se encontrar o sujeito, a língua e a História. (GREGOLIN, 2005, p. 32)

Problematizando a questão um pouco mais, vale evocar a discussão que Derrida (1992) propõe a respeito de gênero. Para o autor, não se pode, certamente, conceber um texto sem gênero. Mas também não se pode dizer que um determinado texto pertença, propriamente, a determinado gênero. Antes, o gênero participa de um ou vários gêneros. Seguindo, pois, o raciocínio de Derrida, que usa o gênero do romance como exemplo, tomemos a designação "lenda urbana". De uma forma ou de outra, ela pressupõe uma marca, ainda que não explicitamente rotulada, ou ainda que atribuída de forma confusa ou irônica. Essa marca, no entanto, não encerra em si uma finalidade, um acabamento completo. Ela opera em suas fronteiras simultaneamente uma inclusão e uma exclusão em relação ao gênero como categoria. Em outras palavras, a designação marca e ao mesmo tempo demarca um lugar de significação. Esse lugar de significação reúne o corpus sob uma identificação provisória (uma legenda), mas no mesmo movimento, impede-o de se fechar, de se identificar consigo mesmo. Assim, a lenda não pertence ao corpus. Ela é instituída pelo corpus ao mesmo tempo em que o sustenta. Instaura sua própria condição de possibilidade e reconhece a impossibilidade de uma taxonomia categórica. 
Podemos dizer que o gênero, dessa forma, funciona analogamente ao arquivo, assim descrito pelo próprio autor em um outro ensaio:

[...] todo arquivo [...] é ao mesmo tempo instituidor e conservador. Revolucionário e tradicional. Arquivo eco-nômico neste duplo sentido: guarda, põe em reserva, economiza, mas de modo não natural, isto é, fazendo a lei (nomos) ou fazendo respeitar a lei. (DERRIDA, 1995/2001, p. 17, grifos do autor)

$\mathrm{O}$ arquivo, enfim, não se fecha numa coleção; demanda sempre e está sempre pronto a incorporar novo material.

\section{CONSIDERAÇÕES FINAIS}

A partir da discussão que vimos traçando, é possível concluir que a indeterminação e heterogeneidade dos gêneros, antes de serem fatores complicadores para a delimitação das lendas urbanas, é uma condição inescapável dos processos discursivos por meio do qual elas - e qualquer outro gênero narrativo, afinal de contas - se constituem. De uma forma ou de outra, todos os autores discutidos aqui levam em conta essa preocupação. A relativa estabilidade das formas genéricas - já descrita na definição clássica de gênero tal como se encontra em Bakhtin (19521953/2000, p. 279-287): "tipos relativamente estáveis de enunciados... formas típicas de enunciado" - deve, portanto, ser enfatizada sob dois pontos de vista. Por um lado, é preciso trabalhar com categorias a priori que permitam a própria operação da análise, isto é, a "ancoragem, ou lei interpretativa" - aqui temos um rumor, acolá provavelmente uma lenda, por exemplo. Por outro lado, não se pode jamais perder de vista o "trânsito interpretativo" resultante da fluidez dessas categorias, de sua composição heterogênea por natureza, tanto no sentido de não serem formas "puras" por si sós, quanto no sentido de que estão constantemente articuladas com outras categorias afins, compartilhando o espaço discursivo em que circulam - aqui temos uma notícia de jornal contendo simultaneamente um rumor $\mathrm{e}$ um relato factual, por exemplo.

É dentro desse fluxo constante da interpretação que propusemos aqui um olhar, ainda que introdutório, sobre um gênero ainda pouco estudado no Brasil e que, no entanto, acreditamos, parece clamar por um 
lugar "de direito" entre os gêneros narrativos em ampla circulação em uma sociedade midiática como a nossa.

\section{REFERÊNCIAS}

ARISTÓTELES. Arte retórica e arte poética. Rio de Janeiro: Ediouro, [s.d.].

BAKHTIN, M. O discurso no romance. In: . Questões de literatura e estética. 2. ed. São Paulo: Editora da UNESP; Hucitec, 1934-1935/1990.

. Os Gêneros do Discurso. In: Estética da criação verbal. 3 . ed. São Paulo: Martins Fontes, 1952-1953/2000.

BARTHES, R. Estrutura da notícia. In: Crítica e verdade. São Paulo: Perspectiva, 1966/2003.

BRUNER, J. A interpretação narrativa da realidade. In: A cultura da educação. Porto Alegre: Artes Médicas, 1996/2001.

BRUNVAND, J. H. The vanishing hitchhicker: American urban legends \& their meanings. New York: W.W. Norton \& Company, 1981.

. Encyclopedia of urban legends. New York: W.W. Norton \& Company, 2002.

DÉGH, L. Legend and belief: dialectics of a folklore genre. Bloomington: University of Indiana Press, 2001.

DERRIDA, J. Acts of literature. New York; London: Routledge, 1992.

Mal de arquivo: uma impressão freudiana. Rio de Janeiro: Relume Dumará, 1995/2001.

ELLIS, B. Aliens, ghosts, and rituals: legends we live. Jackson: University Press of Mississsippi, 2001.

FINE, G. A. Manufacturing tales: sex and money in contemporary legends. Knoxville: The University of Tennessee Press, 1992.

FULFORD, R. The triumph of narrative: storytelling in the age of mass culture. New York: Broadway Books, 1999.

GREGOLIN, M. R. Nas malhas da mídia: agenciando os gêneros, produzindo sentidos. In: BARONAS, R. L. (Org.). Identidade cultural e linguagem. Cáceres: Unemat Editora; Campinas: Pontes, 2005. 
GRILLO, S. V. A Produção do real em gêneros do jornal impresso. São Paulo: Humanitas, 2004.

ORLANDI, E. Discurso e texto: formulação e circulação de sentidos. Campinas: Pontes, 2001.

PINHEIRO, N. F. A noção de gênero para análise de textos midiáticos. In: MEURER, J. L.; MOTTA-ROTH, D. (Orgs.). Gêneros textuais. Bauru: EDUSC, 2002.

WHATLEY, M H.; HENKEN, E. R. Did you hear about the girl who...? Contemporary legends, folklore, and human sexuality. New York; London: New York University Press, 2000.

Recebido em 23/03/08. Aprovado em 11/06/08.

Title: In search of the genre 'urban legend'

Author: Carlos Renato Lopes

Abstract: The present essay aims at locating, from a theoretical point of view, a narrative genre in widespread circulation in contemporary societies, particularly in the virtual media: the so-called urban legends. Firstly, we discuss different definitions of urban legends - proposed within distinct research areas, such as folklore studies and sociology -, with a focus on the discursive aspects involved in the constitution of the genre. Secondly, we explore the boundaries and intersections between this and two similar, and frequently confused genres: the rumor and the fait divers. We conclude our discussion by reviewing and questioning the very issue of the delimitation of a genre.

Keywords: discourse; genre; urban legend; rumor; fait divers.

Titre: À la recherche du genre légende urbaine

Auteur: Carlos Renato Lopes

Résumé: Cet essai a comme objectif situer, du point de vue théorique, un genre narratif en large circulation dans les sociétés contemporaines, surtout dans les milieux virtuels: ce qu'on appelle légendes urbaines. Tout d'abord, on discute plusieurs définitions de légende urbaine - proposées dans des champs de recherche distincts, comme les études de folklore et la sociologie -, cherchant à donner accent aux aspects discursifs impliqués dans la constitution du genre. Ensuite, on exploite les limites et les intersections entre celui et autres deux genres du même avis et souvent confondus: la rumeur et le fait divers. On conclut la discussion à travers une révision et un questionnement de la propre problématique de la délimitation d'un genre discursif.

Mots-clés: genre textuel; légende urbaine; rumeur; fait divers; discours.

Título: En busca del género leyenda urbana

LOPES - Em busca do gênero... 
Autor: Carlos Renato Lopes

Resumen: El presente ensayo tiene como objetivo situar, desde el punto de vista teórico, un género narrativo en amplia circulación en las sociedades contemporáneas, en especial en los medios virtuales: las llamadas leyendas urbanas. En un primer momento, son discutidas diferentes definiciones de leyenda urbana - propuestas dentro de campos de investigación distintos, como los estudios de folklore y la sociología -, buscando dar énfasis a los aspectos discursivos implicados en la constitución del género. Enseguida, son explorados los límites e intersecciones entre ese y otros dos géneros afines y frecuentemente confundidos: el rumor y el fait divers. Se concluye que la discusión por medio de una revisión y cuestionamiento de la propia problemática de la delimitación de un género discursivo.

Palabras-clave: género textual; leyenda urbana; rumor; fait divers; discurso. 